\title{
Modified Bagasse Sheet with Functionalized Silanes for Removing of Engine Oil
}

\author{
S. Kamel, A.A. El-Gendy ${ }^{\#}$ M. El-Sakhawy and M.N. \\ Belgacem* \\ Cellulose \& Paper Department, National Research Centre, 33 \\ Bohouth St. Dokki, Giza. Egypt and * LGP2, Laboratory of Pulp \\ and Paper Science, 461, rue de la papeterie, BP65, 38402 St- \\ Martin-d'Heres Cedex, France.
}

\begin{abstract}
SURFACE modification of bagasse paper sheet was carried out using silane derivatives, n-octyl triethoxysilane or perfluoro octyltriethoxy silane, in an ethanol/water medium. The change of sheet surface properties after modification was ascertained by contact angle measurements, scanning electron microscopy and FTIR. The capability of the treated bagasse sheet to absorb engine oil from aqueous solution was studied. It was found that the treated sheet was significantly more hydrophobic than the untreated sheet. Treated sheet had little affinity for water and good affinity for oil.
\end{abstract}

Keywords: Bagasse paper sheet, Silane derivatives, Engine oil, Contact angle and FTIR.

When oil is spilled into an aquatic environment, it can harm living things because its chemical constituents are poisonous. This can affect organisms both from internal exposure to oil through ingestion or inhalation and from external exposure through skin and eye irritation. Oil can also smother some small species of fish or invertebrates and coat feathers and fur, reducing birds' and mammals' ability to maintain their body temperatures. Spilled oil can also damage parts of the food chain, including human food resources.

Gas station runoff is one of the major sources that contribute oil to waters. For this looming danger, it needs to treat waste water to reduce the concentrations of the pollutants to tolerable levels as approved by national and international guidelines and standards for polluted waters before their final discharge into the environment. Plant materials have long been used as sorbents for oil spill cleanup in which oil concentration is relatively high ${ }^{(1-5)}$. The importance of systematic utilization of sugar cane bagasse has been noted in the past decade. Environmental concerns have focus not only for the quantity of bagasse produced annually but also for the nature of the material ${ }^{(6-8)}$. Moreover, a limited number of studies on the application of plant biomass to remove low oil concentration from storm water runoff have been conducted ${ }^{(1,9-12)}$. 
A broad variety of chemical modification reactions of cellulose both at the $\mathrm{OH}$ groups and the $\mathrm{C}$ atoms are possible. Cellulose is not only the most abundant organic polymer but also a very uniform macromolecule consisting of $\beta$ - (1-4)linked anhydroglucose repeating units. One of this, modification of bagasse is acylation grafting with a fatty acid which produced a material significantly more hydrophobic than the bagasse starting material. This grafted bagasse had little affinity for water and good affinity for oil, while raw bagasse absorbed water also. Hence the grafted raw bagasse would be most suitable for applications where oil is to be removed from an aqueous environment. For oil absorbing applications in the absence of water, the raw bagasse was found to be an excellent material ${ }^{(13)}$. Another treatment is using trialkoxysilanes, R'Si(OR) ${ }_{3}$, which are widely used in numerous industrial applications as coupling agents. The alkoxy groups OR enable the silane to be anchored to surfaces bearing hydroxyl groups ${ }^{(14-16)}$. On the other hand, the organic functionality R' (amine, methacrylic, vinylic..., etc.) improves their compatibility, or even copolymerizes with organic matrices, thus enhancing the interfacial adhesion between the two phases ${ }^{(17)}$. Usually, the surface treatment is carried out with a silane wateralcohol solution in a concentration range of $0.5-2 \%$ by weight. These conditions offer several advantages, in particular (i) an increase of silane solubilization in the medium, (ii) better control of the film thickness on the surface, and (iii) more uniform coverage of the surface. The water induces stepwise hydrolysis of the silane ${ }^{(14,18)}$ to give the corresponding silanol derivative $\mathrm{R}^{\prime}-\mathrm{Si}(\mathrm{OH})_{3}$, which promotes the silane adsorption onto $\mathrm{OH}$-rich substrates through hydrogen bonding. The actual chemical condensation is known to occur after thermal activation, leading to siloxane bridges ${ }^{(19-21)}$ as follows:

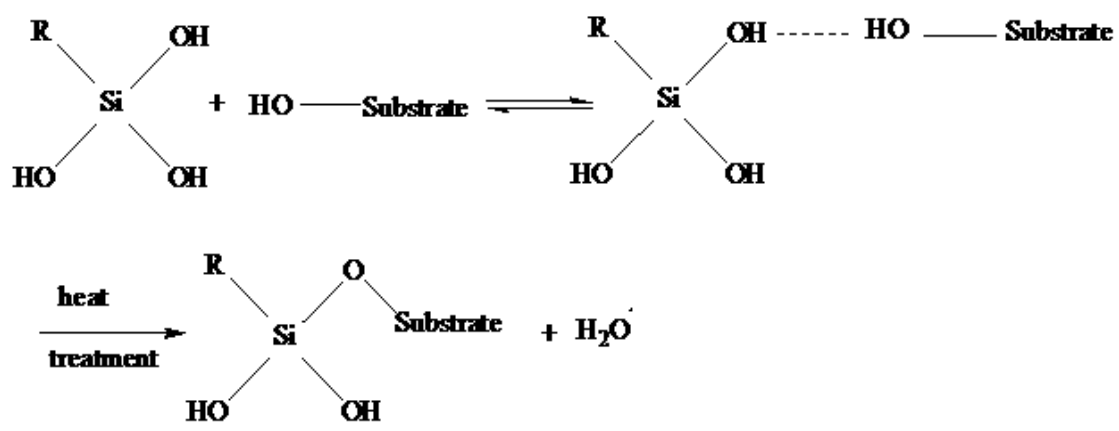

Rapid and efficient approach to the hydrophobization and lipophilization of cellulose fibers by their reaction with gaseous trichloromethylsilane was also developed recently ${ }^{(22)}$. Avicell cellulose, as well as that of Whatman paper were grafted by two fluorine-bearing alkoxysilane, namely: 3,3,3-trifluoropropyl trimethoxysilane and $1 \mathrm{H}, 1 \mathrm{H}, 2 \mathrm{H}, 2 \mathrm{H}$, perfluorooctyl trimethoxysilane to increase the lipophilicity of cellulose ${ }^{(23)}$. Also, other research groups started focusing on making paper superhydrophobic. In one study, in-situ atom transfer radical polymerization was used to graft and grow a polymer layer with nanoscale roughness on a fiber surface, which led to superhydrophobicity (water contact

Egypt. J. Chem. 58, No. 3 (2015) 
angles $\left.>160^{\circ}\right)^{(24)}$. In another study, polymethyl silsesquioxane coatings were covalently bonded onto the cellulose fiber surfaces via a polycondensation reaction between the hydroxyl groups of silanol and cellulose ${ }^{(25)}$.

Deposition of this low surface energy film also resulted in the formation of nano-scale roughness resulting in a superhydrophobic paper surface with a contact angle of $157^{\circ}{ }^{(26)}$. However, due to the nanoscale roughness of the surfaces in the above two methods is associated with a deformable polymer film, robustness and durability are limited. Superhydrophobicity was also imparted onto paper surfaces by depositing nano-scale silica particles on the fibers using sol-gel approaches and fluorinating the resulting surface using perfluorooctyltriethoxysilane to obtain low surface energy ${ }^{(27)}$. The present study deals with the surface modification of bagasse paper sheet with n-octyl triethoxysilane and perfluoro octyltriethoxy silane. The main objective of this study is to investigate the possibility of using treated bagasse paper sheet to remove engine oil from aqueous solution. The structure of siloxanes used in this work is presented as follows:

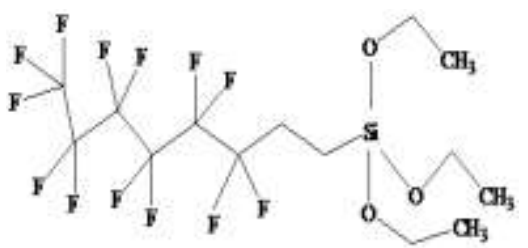

Perfluoro octyltriethoxy silane

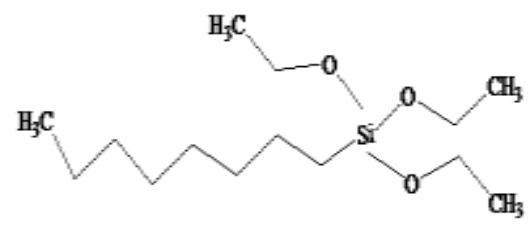

n-octyl triethoxysilane

\section{Experimental}

Unbleached Kraft bagasse pulp is kindly provided by Idfo Company, Egypt. n-octyl triethoxysilane, perfluoro octyltriethoxy silane (Sigma) are used without further purification.

\section{Preparation of paper sheets}

The conventional hand sheets with a basis weight of $60 \mathrm{~g} / \mathrm{m}^{2}$ were prepared on a Rapid Khöten sheet former following the standard method IS0 5269-2:2004. The pulp drainability was adjusted to Shopper Riegler degree 40R (SR-ISO $5267-1)$. Before testing, the hand sheets were conditioned $\left(23{ }^{\circ} \mathrm{C}, 50 \%\right.$ relative humidity-ISO 187,1990).

\section{Modification by silane derivatives}

Ethanol-water 20/80 (w/w) solution of n-octyl triethoxysilane and perfluoro octyltriethoxy silane was prepared. Their grafting was realized by adding the previously prepared solution of silane to the paper sheet. The resulting suspensions were kept at room temperature, for $2 \mathrm{hr}$, under gentle stirring. At the end of the reaction, paper sheet was isolated then submitted, for $2 \mathrm{hr}$, to a heat treatment at $110^{\circ} \mathrm{C}$ in order to induce grafting, as reported elsewhere ${ }^{(28)}$. 


\section{Characterization}

FTIR analysis

The FTIR spectra were obtained with a Perkin-Elmer BX II spectrophotometer used in transmission mode with a resolution of $2 \mathrm{~cm}^{-1}$ in the range of $400-4000 \mathrm{~cm}^{-1}$.

\section{Contact angle measurements}

Dynamic contact angle measurements were performed using a Dataphysics OCA 20 apparatus. A calibrated droplet of water was deposited on the surface of paper sheet and the evolution of the contact angle with time was recorded using a CCD camera with an automatic acquisition of 50 images per second.

\section{Scanning electron microscopy (SEM)}

The surface morphology of non-grafted, and grafted bagasse paper sheet were analyzed using electron microscope FEI INSPECTS Company, Philips, Holland, environmental scanning without coating.

\section{Adsorption studies}

Approximately $100 \mathrm{ml}$ of oil was placed in $250 \mathrm{ml}$ glass beaker. A preweighed adsorbent paper (raw or modified) was placed in the beaker containing oil and a thin wire was used to immerse the paper into the oil up to $2 \mathrm{~cm}$ from the top of the paper. After a specified time (10, 20, 30, 40, 60, 80, 100 and 120 second), the sorbent was then removed from the beaker. The excess unabsorbed oil was drained for five minutes, and the sorbent was weighed.

The oil absorption capacity was determined from the equation:

$$
\text { Cade }=\frac{w_{2}-w_{1}}{w_{1}} \mathrm{~g} / \mathrm{g}
$$

where: Cads is the oil absorption capacity in $\mathrm{g} / \mathrm{g}$. W1 and W2 are the weights of paper before and after oil sorption, respectively ${ }^{(29)}$.

\section{Results and Discussion}

\section{Paper sheet modification}

Although hydrophilicity and hydrophobicity are defined as displaying a water contact angle less than and greater than $90^{\circ}$, respectively, these terms should be considered only in a relative sense. Pure cellulose is hydrophilic in nature with a water contact angle of $\sim 20^{\circ}$. But, depending upon the pulping techniques used, the pulp will contain different proportions of cellulose lignin, hemicellulose and extractives which may affect the wettability of the final paper. The contact angle is a quantitative measure of the wettability of a solid surface by a liquid. The contact angle $\theta$ is the angle formed by a liquid drop at the liquid, gas and solid three-phase boundary. It is included between the tangent plane to the surface of the liquid and the tangent plane to the surface of the solid, at the point of intersection $^{(30)}$. 
The attempts to prepare hydrophobic paper sheet by n-octyl triethoxysilane and perfluoro octyltriethoxy silane were made from water ethanol mixtures for favoring the formation of hydrophobic domains. The time and amount of silane derivatives were varied. Ethanol water mixture containing $20 \mathrm{vol} \%$ of $\mathrm{EtOH}$ was used in all experiments as solvent. Paper sheets were treated by impregnation with ethanol solutions of silane derivatives. All treated materials became highly hydrophobic which can be seen from Table1.

TABLE 1. Contact angles of water drops on untreated and n-octyl triethoxysilane and perfluoro octyltriethoxy silane treated paper sheets for different impregnation time.

\begin{tabular}{|c|c|c|c|c|c|c|}
\hline \multirow{3}{*}{$\begin{array}{l}\text { Impregnation } \\
\text { time (min) }\end{array}$} & \multicolumn{6}{|c|}{ Contact angle $\left(\theta^{\circ}\right)$} \\
\hline & \multicolumn{3}{|c|}{ Perfluoro octyltriethoxy silane } & \multicolumn{3}{|c|}{ n-octyl triethoxysilane } \\
\hline & $40 \mathrm{mM} / \mathrm{L}$ & $30 \mathrm{mM} / \mathrm{L}$ & $20 \mathrm{mM} / \mathrm{L}$ & $40 \mathrm{mM} / \mathrm{L}$ & $30 \mathrm{mM} / \mathrm{L}$ & $\begin{array}{c}20 \\
\mathrm{mM} / \mathrm{L}\end{array}$ \\
\hline 00 & 48.36 & 48.36 & 48.36 & 48.36 & 48.36 & 48.36 \\
\hline 30 & 97.00 & 107.00 & 108.09 & 72.00 & 75.00 & 72.30 \\
\hline 60 & 102.25 & 118.20 & 105.00 & 93.00 & 98.00 & 96.89 \\
\hline 90 & 105.07 & 109.00 & 105.70 & 110.00 & 113.64 & 101.47 \\
\hline
\end{tabular}

Figure 1 shows photos of representative water droplets on paper sheets, untreated, treated by $30 \mathrm{mM} / \mathrm{L}$ n-octyl triethoxysilane for $90 \mathrm{~min}$ and treated by $20 \mathrm{mM} / \mathrm{L}$ perfluoro octyltriethoxy silane for $20 \mathrm{~min}$. As expected, before esterfication paper sheet was hydrophilic. The contact angle of water droplet deposited at its surface was $48.36^{\circ}$. After treatment with n-octyl triethoxysilane and perfluoro octyltriethoxy silane, the contact angle increased very significantly from 48.36 to 113 and 118 , respectively. Increasing concentration of n-octyl triethoxysilane and perfluoro octyltriethoxy silane from $20 \mathrm{mM} / \mathrm{L}$ to $40 \mathrm{mM} / \mathrm{L}$ has no significant effect on increasing contact angle. For n-octyl triethoxysilane contact angle increases as the impregnation time increases from 0 to $90 \mathrm{~min}$, while for perfluoro octyltriethoxy silane impregnation time more than $30 \mathrm{~min}$ has no noticeable effect. Moreover, the evolution of the contact angle of a drop of water deposited on the surface of paper before and after treatment shows that the penetration and/or the spreading of the liquid were reduced significantly. In general, the contact angles of treated sheet with perfluoro octyltriethoxy silane were higher than that with n-octyl triethoxysilane under the same reaction condition.

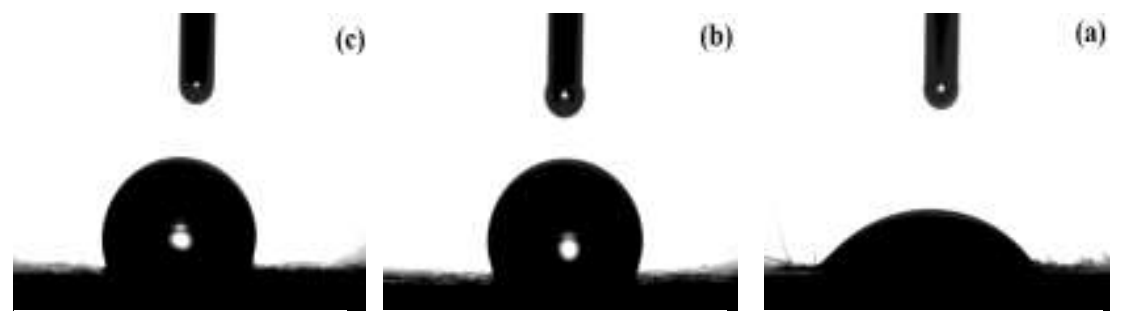

Fig. 1. Photos of representative water droplets on (a) untreated (b) $30 \mathrm{mM} / \mathrm{L}$ n-octyl triethoxysilane for $90 \mathrm{~min}$ and (c) $20 \mathrm{mM} / \mathrm{L}$ perfluoro octyltriethoxy silane for 20 min treated paper sheets. 
FT-IR spectra

Different techniques were used to characterize the modified paper. The FT-IR spectrum is one of these techniques. Figure 2 shows the FTIR spectra of the untreated and treated handsheets. Treatment of the handsheet results in reduce of cellulose absorption bands: $3348 \mathrm{~cm}^{-1}(\mathrm{O}-\mathrm{H}$ stretch$), 1336 \mathrm{~cm}^{-1}(\mathrm{O}-\mathrm{H}$ in-plane deformation), $2902 \mathrm{~cm}^{-1}$ (C-H stretch), $1430 \mathrm{~cm}^{-1}$ (C-H deformation, asymmetric) and $1059 \mathrm{~cm}^{-1}$ (C-O stretch), which indicates a reduced level of oxygen and hydrogen present on the surface. The presence of new absorption bands at $1200 \mathrm{~cm}^{-1}$ (CFx stretch) confirms the presence of a fluorocarbon bond. Thus, the spectrum of the handsheet after treatment exhibits features of both an untreated and treated sheets ${ }^{(30)}$.

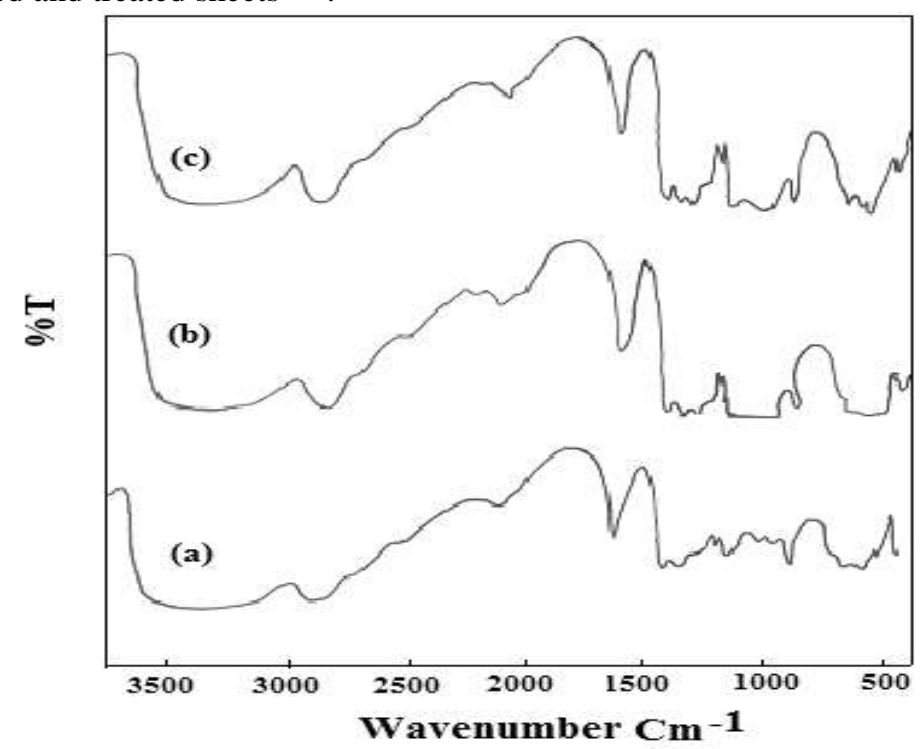

Fig. 2. FTIR spectroscopy of untreated and treated paper sheet with n-octyl triethoxysilane and perfluoro octyltriethoxy silane.

\section{Morphological investigation}

The ever rising need for detailed knowledge of the structure of paper coating urges the improvement and development of new techniques for gaining new and valuable information. The assessment, study and characterization of factors that are assumed to affect the coated paper surface may be accomplished by microscopy and image analysis techniques. The scanning electron microscope (SEM) is a most suitable tool for morphometrical studies of fibers and paper. Figure 3 exhibits the SEM images of the paper before and after treatment with noctyl triethoxysilane and perfluoro octyltriethoxy silane which reveals a clear-cut distinction between the scanning electron micrographs of original paper sheet and treated sheets. From the SEM images it is evident that these substrates have very different surface roughness values prior to treatment with n-octyl triethoxysilane and perfluoro octyltriethoxy silane.

Egypt. J. Chem. 58, No. 3 (2015) 

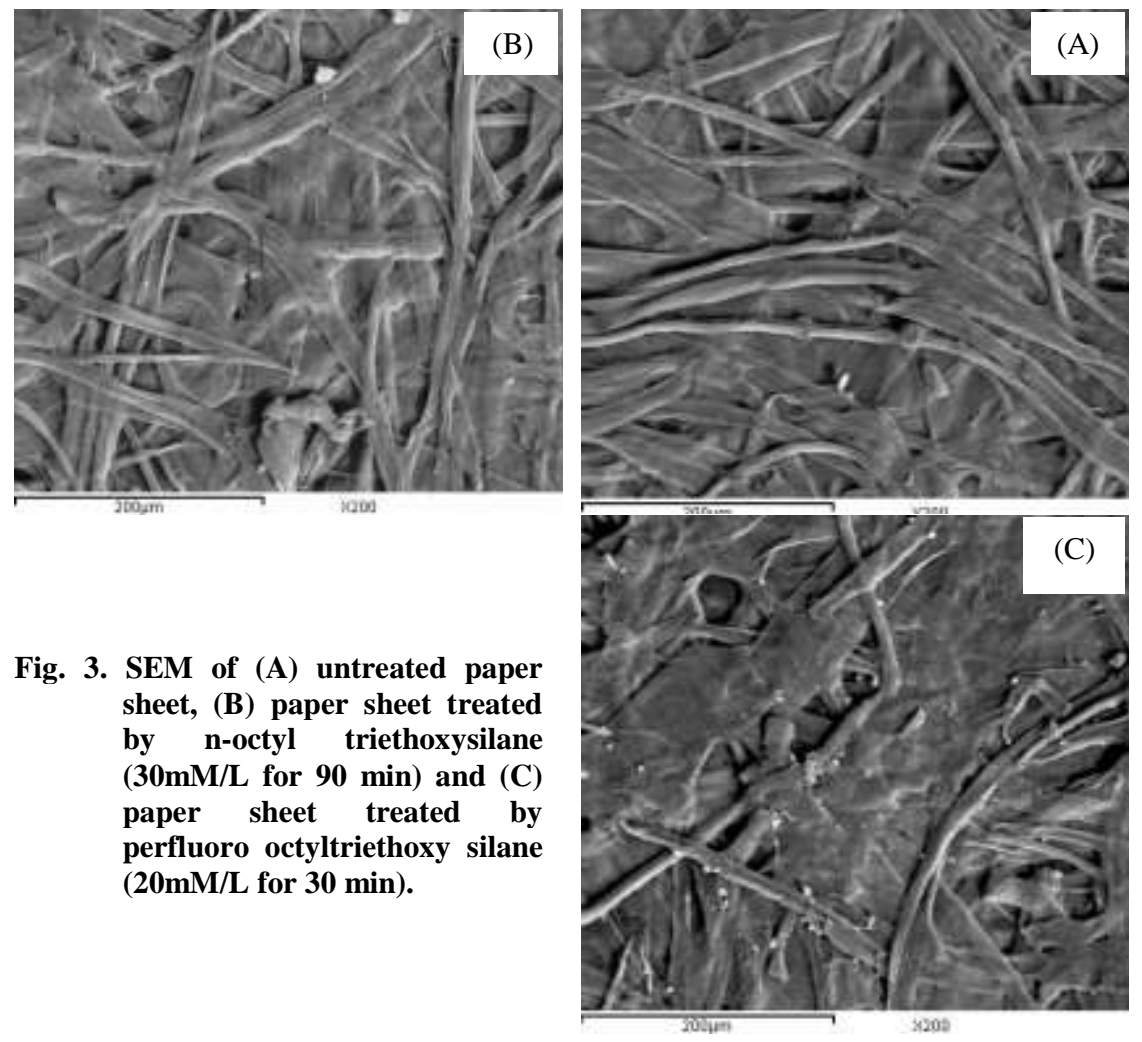

Fig. 3. SEM of (A) untreated paper sheet, (B) paper sheet treated by n-octyl triethoxysilane $(30 \mathrm{mM} / \mathrm{L}$ for $90 \mathrm{~min})$ and $(\mathrm{C})$ paper sheet treated by perfluoro octyltriethoxy silane (20mM/L for $30 \mathrm{~min})$.

\section{Oil sorption test}

Raw bagasse is a combination of cellulose, lignin, and other minor components. It is a material that absorbs hydrophilic and hydrophobic materials. Pulping of bagasse removes lignin and other non-cellulose components, resulting in a largely cellulosic material called pulp. Cellulose macromolecules are more attracted to hydrophilic than to hydrophobic materials. The hydrophobic parts of the cellulose molecule are mostly covered by the hydroxyl groups extending from the six-member rings of the cellulose polymer chain ${ }^{(13)}$. The treatment of paper sheets by n-octyl triethoxysilane, and perfluoro octyltriethoxy silane built relatively long hydrophobic chains. This hydrophobic envelope would be attractive to oil and apparently contributes to the oil absorbing properties of the modified paper sheet.

Figure 4 shows the overall results of the sorption behavior of different sorbents tested. It is clear that by increasing the dipping time the adsorption capacity for engine oil by untreated and treated paper sheets increases. Paper sheets treated by n-octyl triethoxysilane $(30 \mathrm{mM} / \mathrm{L}$ for $90 \mathrm{~min})$, and perfluoro octyltriethoxy silane $(20 \mathrm{mM} / \mathrm{L}$ for $30 \mathrm{~min})$ exhibited high capabilities for oil removal than unmodified paper. On comparing the absorption capacity of sorbents to engine oil, perfluoro octyltriethoxy silane showed the highest oil 
sorption capacity for engine oil followed by n-octyl triethoxysilane modified sheets. The oil sorption values of untreated paper sheet were generally lower compared to those of modified ones. Thus, sheets treated by n-octyl triethoxysilane, and perfluoro octyltriethoxy silane stearic were found the best performing materials for removing of engine oil.

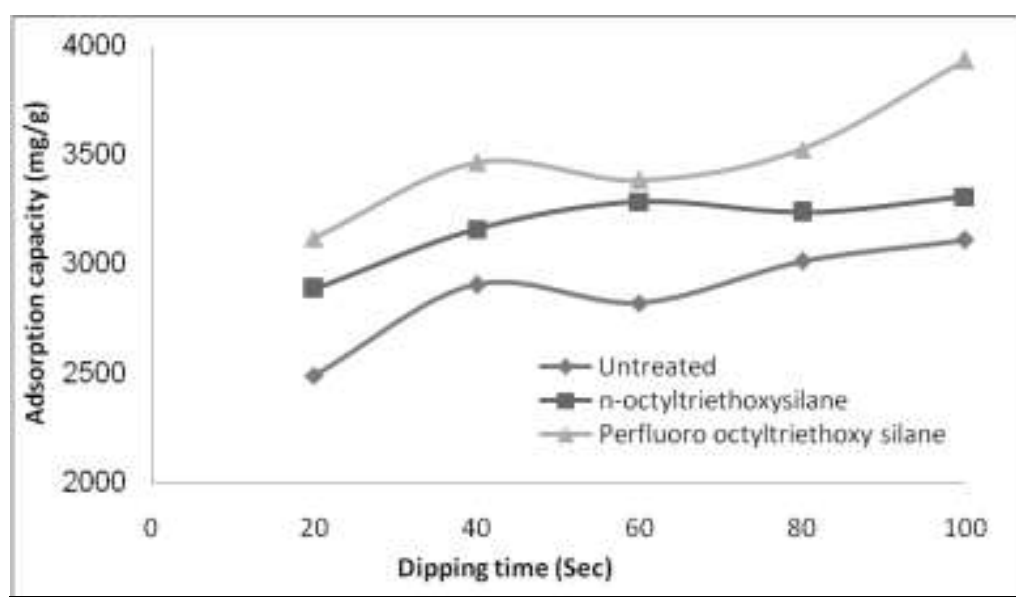

Fig. 4. Effect of dipping time on adsorption capacity of engine oil by untreated and treated paper sheets.

\section{Conclusion}

The surface modification of bagasse paper sheets by n-octyl triethoxysilane and perfluoro octyltriethoxy silane increased the contact angle of paper sheets from 48.36 to 113 and 118, respectively. So this treatment increases the hydrophobicity of paper sheets. On comparing the absorption capacity of sorbents to engine oil, perfluoro octyltriethoxy silane showed the highest oil sorption capacity for engine oil followed by n-octyl triethoxysilane modified sheets.

\section{References}

1. Kamel, S., Belgacemt, M.N., El-Sakhawy, M., El-Gendy, A. and Abdel Ghafar, H.H., Effectiveness of treated paper in oil spills cleanup. Advances in Natural and Applied Sciences, 8(5), 354 (2014).

2. Choi, H.M. and Cloud, R.M., Natural sorbents in oil spill cleanup. Environmental Science Technology, 26, 772 (1992).

3. Choi, H.M., Needlepunched cotton nonwovens and other natural fibers as oil cleanup sorbents. Journal of Environmental Science Health, Part A, 31, 1441(1996).

4. Ribeiro, T.H., Smith, R.W. and Rubio, J., Sorption of oils by the nonliving biomass of a Salvinia sp. Environmental Science Technology, 34, 5201 (2000).

Egypt. J. Chem. 58, No. 3 (2015) 
5. Deschamps, G., Caruel, H., Borredon, M.E., Bonnin, C. and Vignoles, C., Oi removal from water by selective sorption on hydrophobic cotton fibers. 1. Study of sorption properties and comparison with other cotton fiber-based sorbents. Environmental Science Echnology, 37, 1013 (2003).

6. Taylor, A.K., From raw sugar to raw materials. Chemical Innovation, 30(11), 45 (2000).

7. Ritter, S.K., Biofuel bonanza. Chemical and Engineering News, 85(26), 15 (2007).

8. Hamid, S., Javad, T. and Reza, B., Oil by-product removal from aqueous solution using sugarcane bagasse as absorbent. International Journal of Emerging Science and Engineering (IJESE), 2(9), 2319 (2014).

9. Stenstrom, M.K., Silverman, G.S. and Bursztynsky, T.A., Oil and grease in urban storm waters. Journal Environmental Engenering ASCE, 110, 58 (1984).

10. Lopes, T.J., Fallon, J.D., Rutherford, D.W. and Hiatt, M.H., Volatile organic compounds in storm water from a parking lot. Journal of Environmental Engenring ASCE, 126, 1137 (2000).

11. Kayhanian, M., Khan, S. and Stenstrom, M.K., A New Method to Estimate Oil and Grease Event Mean Concentration in Roadway Runoff. Proceeding, Storm Con, Palm Desert, CA, July 26-29 (2004).

12. Eakalak, K., Wanpen, V. and Thunyalux, R., Use of biomass sorbents for oil removal from gas station run off. Chemosphere, 57, 681(2004).

13. Abd El-Aziz, A., Said, A., Adriane, G., Ludwick, B. and Heshmat, A.A. Usefulness of raw bagasse for oil absorption: a comparison of raw and acylated bagasse and their components. Bioresource Technology, 100, 2219 (2009).

14. Ishida, H. and Koenig, J. L., Vibrational assignments of organosilanetriols. I. vinylsilanetriol and vinylsilanetriol- $\mathrm{d}_{3}$ in aqueous solutions. J. Applied Spectroscopy, 32(5), 462 (1978).

15. Rodriguez, M.A. and Liso, M.J., Study of the reaction of $\gamma-$ methacryloxypropyltrimethoxysilane $(\gamma-$ MPS) with slate surfaces. Journal of Material Science, 34, 3867 (1999).

16. Marie-Christine, B., Salon, G.G., Abdelmouleh, M., Cécile, B., Sami, B. and Mohamed, N.B., Studies of interactions between silane coupling agents and cellulose fibers with liquid and solid-state NMR. Magnetic Resonance in Chemistry, 45 (6), 473 (2007).

17. Chaudhury, M.K., Gentl, T.M. and Plueddmann, E.P., Adhesion mechanisms of polyvinyl chloride to silane primed metal surfaces. J. Adhesion Sci. Tech. 1, 29 (1986).

18. Chu, C.W., Kirby, D.P. and Murphy, P.D., Interactions of aminosilane with alumina and silica substrates deposited from nonaqueous and aqueous media. Journal of Adhesion Science Technology, 7 (5), 417 (1993).

Egypt. J. Chem. 58, No. 3 (2015) 
19. Nishiyama, N., Horie, K. and Asakura, T., Adsorption behavior of a silane coupling agent onto a colloidal silica surface studied by ${ }^{29} \mathrm{Si}$ NMR spectroscopy. Journal of Colloid and Interface Science, 129(1), 113(1989).

20. Marie-Christine, B., Abdelmouleh, M., Sami, B., Mohamed, N.B. and Alessandro, G., Silane adsorption onto cellulose fibers: Hydrolysis and condensation reactions. Journal of Colloid and Interface Science, 289, 249(2005).

21. Daniels, M.W. and Francis, L.F., Silane adsorption behavior, microstructure, and properties of glycidoxypropyltrimethoxysilane-modified colloidal silica coatings. Journal of Colloid Interface Science, 205, 191 (1998).

22. Khalil, H.P.S., Davoudpour, Y., Nazrul, M.D., Asniza, M. A., Sudeshd, K., Dungani, R. and Jawaidb, M., Production and modification of nanofibrillated cellulose using various mechanical processes: A review. Carbohydrate Polymers, 99, 649 (2014).

23. Ly, E.H.B., Belgacem, M.N., Bras, J. and Brochier-Salon, M.C., Grafting of cellulose by fluorine-bearing silane coupling agents. Materials Science and Engineering C: Materials for Biological Applications, 30, 343 (2010).

24. Yang, H. and Deng, Y., Preparation and physical properties of superhydrophobic papers. Journal of Colloid and Interface Science, 325(2), 588 (2008).

25. Gen, H., Kazuyoshi, K., Kentaro, A., Hiroyuki, Y., Ayaka, M., Hironori, K. and Kazuki, N., Polymethylsilsesquioxane-cellulose nanofiber biocomposite aerogels with high thermal insulation, bendability and superhydrophobicity. ACS Appl. Mater Interfaces, 6, 9466 (2014).

26. Deng, B., Ren, C., Yang, Y., Haiqing, J., Chunlei, A., Jiang, L., Linfan, Li. , Ming, Y., Jingye, L., Leidong, X., Qing, H. and Chunhai, F., Laundering durability of superhydrophobic cotton fabric. Adv. Mater. 22, 5473(2010).

27. Nyström, D., Lindqvist, J., Ostmark, E., Hult, A. and Malmstrom, E., Superhydrophobic bio-fibre surfaces via tailored grafting. Architecture Chemical Communications, 34, 3594 (2006).

28. Wei, Q.F., Mather, R.R. and Fotheringham, A.F., Oil removal from used sorbents using a biosurfactant. Bioresource Technology, 96, 331(2005).

29. Kesong, L., Ye, T. and Lei, J., Bio-inspired superoleophobic and smart materials: Design, fabrication and application. Progress in Materials Science, 58, 503(2013).

30. Agraharam, S., Hess, D.W., Kohl, P.A. and Allen S.A.B., Plasma chemistry in fluorocarbon film deposition form pentafluororethane/argon mixtures. Journal of Vacuum Science \& Technology A, 17(6), 3265 (1999). 


\section{ورق مصاص القصب المعالج بمركبات السليكون الوظيفية لازالة زيوت المحركات}

$$
\begin{aligned}
& \text { سمير كامل ، احمد الجندى، محمد السخاوى و ناصر بلقاسم" القرى }
\end{aligned}
$$

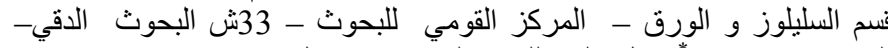

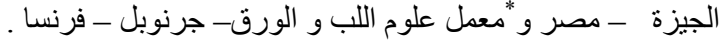

تمت المعالجة السطحية للورق المحضر من لب مصاص القصب باستخدام

المشتقات السيليكونية octyltriethoxy silane,

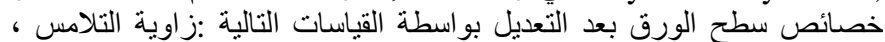

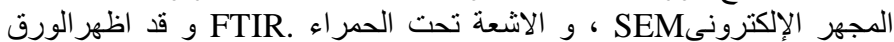

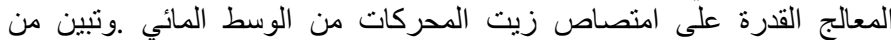

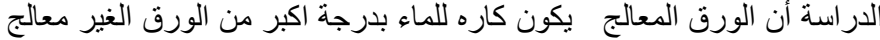

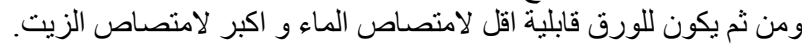

